\title{
Unge kvinners vold mot partner
}

Engelsk oversettelse av hele artikkelen på www.tidsskriftet.no

\section{Sammendrag}

Bakgrunn. Forskningen om kvinner som utøver partnervold er begrenset. I denne studien undersøker jeg hvordan unge kvinners utøvelse av vold mot partneren henger sammen med kjennetegn ved parforholdet og med aggressivitet mer generelt. Videre belyses antakelsen om at selvforsvar ofte er et hovedmotiv for volden.

Materiale og metode. Analysene bygger en landsdekkende longitudinell studie av normalbefolkningen. Data om partnervold ble innhentet da kvinnene var 20-25 år.

Resultater. Av 1250 kvinner som hadde vært i et parforhold siste halvår, hadde 114 (9\%) fiket til partneren i samme periode, mens 70 (6\%) hadde slått, sparket eller bitt. 77 (6\%) oppga at de selv, men ikke partneren, hadde utøvd slik vold, mens 68 (5\%) svarte at angrepene var gjensidige. Volden korrelerte med annen destruktiv samhandling med partneren. Majoriteten av kvinnene som hadde brukt vold, var likevel fornøyd med parforholdet. Både aggresjonsrelaterte personlighetstrekk og utagerende atferd i tenårene var relatert til vold mot partner.

Fortolkning. Unge kvinner som utøver partnervold, er generelt mer aggressive enn kvinner ellers og er i mange tilfeller alene om å være fysisk aggressiv i forholdet. Studien gir lite støtte til antakelsen om at selvforsvar er et hovedmotiv bak voldsbruken. Resultatene må ses i sammenheng med at undersøkelser av normalbefolkningen i liten grad fanger opp virkelig grov partnervold.

\section{Hilde Pape}

hilde.pape@nkvts.unirand.no

Nasjonalt kunnskapssenter om vold og traumatisk stress (NKVTS)

De mest graverende formene for vold i samliv og parforhold handler som oftest om mannlige utøvere og kvinnelige ofre $(1,2)$. Mer utbredt og mindre alvorlig partnervold er det derimot vel så ofte kvinner som menn som står bak (1, 3-5). Kvinners utøvelse av slik vold har vært gjenstand for mindre forskning enn fenomenets forekomst skulle tilsi. I det følgende vil funn fra en norsk studie om temaet bli presentert. Tidligere analyser av det aktuelle datasettet har vist at partnervold ikke rammer blindt og at individer med tendenser til utagering er mer utsatt enn andre (6).

Hensikten med denne artikkelen er å undersøke hvordan unge kvinners utøvelse av slik vold henger sammen med kjennetegn ved parforholdet og med aggressivitet mer generelt. Videre vil antakelsen om at kvinnenes voldsbruk i stor grad finner sted for å beskytte seg mot partnerens fysiske angrep bli belyst.

\section{Materiale og metode}

Data er hentet fra undersøkelsen Ung i Norge, som startet opp i 1992 med et landsrepresentativt utvalg av skoleungdom (responsrate: $97 \%$ ). Den neste datainnsamlingen foregikk i 1994 (responsrate: 92\%). Respondenter som fortsatt var skoleelever i $1994 \mathrm{og}$ som hadde samtykket til videre oppfølging (91\%) mottok spørreskjema i 1999. Av disse svarte $84 \%$ (kumulativ responsrate: $68 \%$ ). Detaljert informasjon om design, datainnsamling og tillatelser finnes andre steder (7).

De fleste analysene bygger på 1999-studien og er begrenset til kvinner som hadde vært $i$ et parforhold siste halvår $(n=1250)$. Videre benyttes data fra 1994 i longitudinelle analyser. I det følgende vil de to måletidspunktene bli omtalt som henholdsvis $\mathrm{t} 2 \mathrm{og}$ $\mathrm{t} 1$. Ved $\mathrm{t} 2$ var respondentene 20-25 år gamle.

Partnervold ble kartlagt på $\mathrm{t} 2$ ved hjelp av to parvise spørsmål om egne og partners fysiske angrep (ørefiker, sparking, biting og/ eller knyttneveslag) det siste halvåret. Spørsmålene stammet fra en modifisert kortversjon av Conflict Tactics Scale (8). I de fleste analysene er to dikotome mål benyttet. Det ene dreier seg om hvorvidt kvinnene hadde utøvd nevnte typer vold minst én gang. Det andre skiller mellom ensidig og gjensidig partnervold.

Uavhengige variabler. Andre spørsmål basert på Conflict Tactics Scale dreide seg om verbal aggressivitet (bannet til, fornærmet) og om å si eller gjøre noe for å være slem mot den andre. Unngåelsesatferd i konfliktsituasjoner (furtet, nektet å snakke) ble også kartlagt. Variablene ble dikotomisert med avskjæringspunktet plassert ved 6+ ganger siste halvår, hvilket innebar at de øverste $10-15 \%$ i fordelingen ble skilt ut.

Hvorvidt partneren ble betraktet som en god støttespiller, ble operasjonalisert som det å ha krysset av for «partner» på følgende spørsmål: Hvem kan få deg til å føle deg bedre hvis du er langt nede og helt på felgen? (spørsmål 1), hvem ville du ha søkt råd eller hjelp hos hvis du hadde et personlig problem? (spørsmål 2) og hvis du var blitt pågrepet av politiet for ulovligheter? (spørsmål 3). Det var 13 svaralternativer og mulig å velge mer enn ett. Opplevd aksept fra partner ble kartlagt på tilsvarende vis, men her ble kun ett spørsmål stilt, nemlig: Hvem godtar deg fullt og helt, både dine gode og dårlige sider? Fordi disse målene refererte til nåvcerende relasjon, ble de bare benyttet $\mathrm{i}$ analyser av kvinner som var i et pågående parforhold. Det samme gjaldt analyser som dreide seg om kvinnenes vurderinger sexlivet og av hele parforholdet. Her ble svarene avgitt på en fempunktsskala, og positive vurderinger ble definert som det å ha krysset av for enten «svært bra» eller «kunne ikke hatt det bedre».

Aggresjonsrelaterte personlighetstrekk ble kartlagt på t 2 ved seks spørsmål fra State Trait Anger Expression Inventory (9). Respondentene anga hvor godt ulike utsagn beskrev dem selv ved å krysse av på en skala

\section{Hovedbudskap}

- Blant unge kvinner i parforhold hadde $11 \%$ angrepet partneren siste halvår

- Ensidige angrep fra kvinnenes side forekom litt oftere enn gjensidig partnervold

- Majoriteten av kvinnene som hadde angrepet partneren, ga uttrykk for at parforholdet fungerte bra

- Kvinner som hadde utøvd partnervold, var generelt mer aggressive enn kvinner ellers 
som gikk fra 1 («passer svært dårlig») til 4 («passer svært godt»). Tre spørsmål målte hissig temperament (f.eks. «Jeg er snarsint») (Chronbachs $\alpha=0,87$ ), de øvrige tre handlet om undertrykt sinne (f.eks. «Jeg bærer ofte nag til andre») (Chronbachs $\alpha=0,61)$. To sumskårer ble konstruert og deretter dikotomisert med avskjæringspunktet plassert ved en gjennomsnittsskår på 3,0 eller mer. Selvvurdert aggressivitet ble kartlagt på både t1 og t2 ved ett spørsmål fra Bem's Sex Role Inventory (10). Variablene ble dikotomisert slik at respondenter som svarte at det stemte «helt» eller «nokså godt» at de hadde denne egenskapen ble skilt ut.

Åtte dikotome variabler fra $\mathrm{t} 1$ dreide seg om utøvelse av problematferd det siste året. For lavprevalent atferd (slåssing, hærverk, mobbing, nasking/stjeling) gikk skillet mellom ingen og $1+$ gang. For mer utbredt problematferd gikk det enten mellom $0-1$ og $2+$ (sniking, lyving) eller mellom $\leq 5$ og 6+ ganger (skoleskulking). Et mål på verbal aggresjon, som ble konstruert på grunnlag av to spørsmål om utagering overfor lærere (voldsom krangling, banning og/eller utskjelling), ble også benyttet ( $\leq 3$ versus $4+$ episoder).

\section{Resultater}

Ved t2 hadde 1272 av kvinnene (78\%) i utvalget vært i et parforhold det siste halvåret. Resultatene i figur 1 viser forekomsten av partnervold i denne gruppen. 114 (9\%) oppga at de hadde fiket til partneren sin minst én gang siste halvår, mens $69(5 \%)$ var blitt utsatt for dette selv. De tilsvarende tallene når det gjaldt slag, bitt eller spark var henholdsvis $70(6 \%)$ og $46(4 \%)$.

77 kvinner (6\%) oppga at bare de selv, og ikke partneren, hadde utøvd noen av de ovennevnte formene for vold, og 68 (5\%) svarte at volden var gjensidig. 22 kvinner (2\%) var blitt utsatt for partnervold uten å ha vært fysisk aggressive selv. Disse ble utelatt fra alle påfølgende analyser. Den resterende gruppen omfattet dermed 1250 kvinner. Gjennomsnittsalderen til disse kvinnene var 22,4 år på t2 og 16,7 år på $\mathrm{t} 1 \quad(\mathrm{SD}=2,0)$. Videre var $971(78 \%)$ i et pågående parforhold, og 561 (45\%) var enten gift eller samboende. $132(10 \%)$ hadde barn. Ingen av disse bakgrunnsvariablene korrelerte med utøvelse av vold mot partner. Blant dem som hadde mottatt trygd eller sosialhjelp hadde $22(19 \%)$ utøvd vold, det samme gjaldt 123 $(11 \%)$ av dem som ikke hadde mottatt slike ytelser $(\mathrm{p}=0,005)$.

Som vist $\mathrm{i}$ tabell 1 var utøvelse av vold mot partneren signifikant relatert til annen destruktiv samhandling med vedkommende. Konfliktnivået var særlig høyt i relasjoner der begge parter hadde vært fysisk aggressive. Disse resultatene gjaldt alle de kvinnene som hadde vært $\mathrm{i}$ et forhold siste halvår $(n=1250)$, men analyser som bare inkluderte kvinner i pågående parforhold, ga til forveksling like funn.
Tabell 2 viser at majoriteten av kvinnene i pågående relasjoner ga uttrykk for at forholdet til partneren var godt. Dette gjaldt også dem som hadde utøvd partnervold. Kvinner som ikke hadde brukt vold, var imidlertid mer tilbøyelige til å fremstille parforholdet sitt på en fordelaktig måte. Unntaket gjaldt det å ha et godt seksualliv, der forskjellen mellom de to gruppene ikke var signifikant. Ytterligere analyser avdekket ingen klare forskjeller mellom kvinner som rapporterte om henholdsvis ensidig og gjensidig voldsbruk, og resultatene er derfor utelatt fra tabellen.

Kvinner som hadde utøvd partnervold, var mer tilbøyelige enn kvinner ellers til å undertrykke sinne og til å ha et hissig temperament (tab 3). De var også mer tilbøyelige til å oppfatte seg selv som aggressive og til å ha vurdert seg selv på samme måte som tenåringer (t1). Videre var forekomsten av ulike former for aggressiv atferd ved t 1 markant forhøyet hos disse kvinnene. Analyser av annen problematferd ved tl pekte i samme retning, men verken sniking eller skulking ga signifikante utslag. Ellers ble ingen klare forskjeller mellom de to utøvergruppene avdekket, bortsett fra hærverk, som ble rapportert av åtte kvinner (10\%) i forhold der volden var ensidig og av $16(24 \%)$ i forhold der den var gjensidig $(\mathrm{p}=0,034)$.

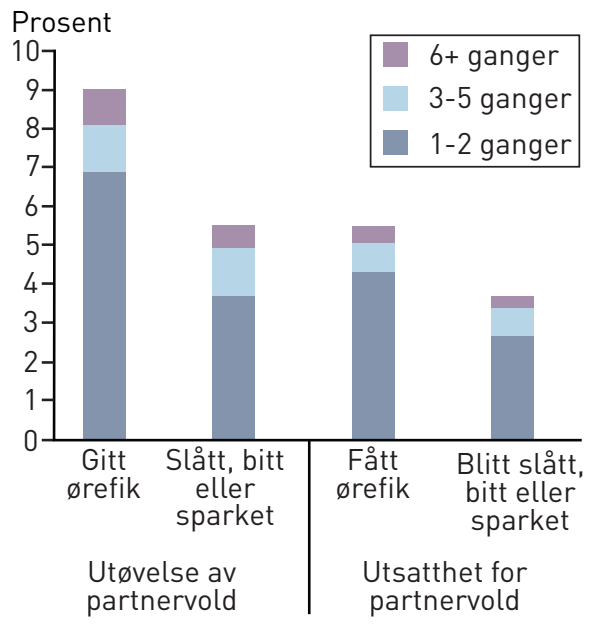

Figur 1 Kvinnenes utøvelse av og utsatthet for ulike former for partnervold siste halvår. Kumulativ prosentfordeling ( $n=1272$ )

\section{Diskusjon}

I tråd med tidligere forskning om partnervold blant unge mennesker $(8,11)$, var gjensidig voldsbruk nesten like utbredt som ensidige angrep fra kvinnenes side. Volden korrelerte med ulike former for destruktiv samhandling med partneren, og konfliktnivået var særlig høyt i relasjoner der begge parter hadde vært fysisk aggressive.

Tabell 1 Egen og partners destruktive konflikthåndtering etter utøvelse av partnervold samt for skjeller mellom kvinner som rapporterte ensidig og kvinner som rapporterte gjensidig voldsbruk. Absolutte tall, prosenter i parentes

\begin{tabular}{|c|c|c|c|c|c|c|c|c|c|c|}
\hline \multirow{3}{*}{ Laveste N } & \multicolumn{5}{|c|}{ Utøvd partnervold } & \multicolumn{5}{|c|}{ Type voldsmønster } \\
\hline & \multicolumn{2}{|c|}{$\begin{array}{c}\mathrm{Nei} \\
1074\end{array}$} & \multicolumn{2}{|c|}{$\begin{array}{l}\mathrm{Ja} \\
139\end{array}$} & \multirow{2}{*}{$\begin{array}{c}\text { P- } \\
\text { verdi }\end{array}$} & \multicolumn{2}{|c|}{$\begin{array}{c}\text { Ensidig } \\
\quad 73\end{array}$} & \multicolumn{2}{|c|}{$\begin{array}{c}\text { Gjensidig } \\
66\end{array}$} & \multirow{2}{*}{$\begin{array}{l}\text { P- } \\
\text { verdi }\end{array}$} \\
\hline & Antall & $(\%)$ & Antall & (\%) & & Antall & (\%) & Antall & $(\%)$ & \\
\hline \multicolumn{11}{|c|}{ Mange verbale angrep/ handlinger for å være slem } \\
\hline Selv & 160 & $(14,7)$ & 80 & $(56,3)$ & $<0,001$ & 36 & $(47,4)$ & 44 & $(66,7)$ & 0,021 \\
\hline Partner & 145 & $(13,5)$ & 68 & $(48,2)$ & $<0,001$ & 27 & $(36,7)$ & 41 & $(61,2)$ & $<0.003$ \\
\hline Begge & 96 & $(8,9)$ & 58 & $(41,7)$ & $<0,001$ & 19 & $(26,0)$ & 39 & $(59,1)$ & $<0,001$ \\
\hline \multicolumn{11}{|c|}{ Mye unngåelsesatferd } \\
\hline Selv & 142 & $(12,9)$ & 47 & $(32,6)$ & $<0,001$ & 20 & $(26,0)$ & 27 & $(40,3)$ & 0,067 \\
\hline Partner & 103 & $(9,5)$ & 40 & $(28,0)$ & $<0,001$ & 12 & $(16,0)$ & 28 & $(41,2)$ & $<0,001$ \\
\hline Begge & 56 & $(5,2)$ & 23 & $(16,2)$ & $<0,001$ & 7 & $(9,3)$ & 16 & $(23,9)$ & 0,019 \\
\hline
\end{tabular}

Tabell 2 Vurderinger av partner, kvaliteten av eget sexliv og av parforholdet generelt etter utøvelse av partnervold. Analyser av kvinner i pågående parforhold. Absolutte tall, prosenter i parentes

Utøvd partnervold

\begin{tabular}{lcccccr} 
& \multicolumn{2}{c}{ Nei } & \multicolumn{3}{c}{ Ja } \\
Laveste N & \multicolumn{2}{c}{862} & & \\
& Antall & $(\%)$ & Antall & $(\%)$ & P-verdi \\
Opplevd støtte fra partner & 652 & $(74,9)$ & 69 & $(62,7)$ & $<0,007$ \\
Opplevd aksept av partner & 739 & $(84,8)$ & 80 & $(72,7)$ & $<0,001$ \\
Både støtte og aksept & 600 & $(68,9)$ & 58 & $(52,7)$ & $<0,001$ \\
\hline Har et godt seksualliv & 532 & $(61,7)$ & 58 & $(52,7)$ & 0,069 \\
Generell positiv vurdering av parforholdet & 679 & $(78,3)$ & 65 & $(59,1)$ & $<0,001$
\end{tabular}


Tabell 3 Aggresjonsrelaterte personlighetstrekk, selvvurdert aggressivitet samt ulike typer problematferd i tenårene etter utøvelse av partnervold. Absolutte tall, prosenter i parentes. Måletidspunktet i kursiv

Utøvd partnervold

\begin{tabular}{|c|c|c|c|c|c|}
\hline \multirow[t]{2}{*}{ Laveste N } & \multicolumn{2}{|c|}{$\begin{array}{c}\mathrm{Nei} \\
1026\end{array}$} & \multicolumn{2}{|c|}{$\begin{array}{c}\mathrm{Ja} \\
127\end{array}$} & \multirow[b]{2}{*}{ P-verdi } \\
\hline & Antall & $(\%)$ & Antall & (\%) & \\
\hline Undertrykker ofte sinne, $t 2$ & 98 & $(8,9)$ & 33 & $(22,8)$ & $<0,001$ \\
\hline Hissig temperament, $t 2$ & 262 & $(23,9)$ & 61 & $(42,4)$ & $<0,001$ \\
\hline Oppfatter seg som aggressiv, t2 & 145 & $(14,1)$ & 45 & $(35,4)$ & $<0,001$ \\
\hline Oppfattet seg som aggressiv, $t 1$ & 364 & $(33,3)$ & 67 & $(46,9)$ & $<0,001$ \\
\hline \multicolumn{6}{|l|}{ Aggressiv problematferd, $t 1$} \\
\hline Vært i slåsskamp & 106 & $(9,8)$ & 32 & $(22,1)$ & $<0,001$ \\
\hline Begått hærverk & 52 & $(4,8)$ & 24 & $(16,6)$ & $<0,001$ \\
\hline Mobbet/plaget andre & 206 & $(25,3)$ & 57 & $(39,3)$ & $<0,001$ \\
\hline Mye verbal aggresjon & 194 & $(18,2)$ & 45 & $(31,0)$ & $<0,001$ \\
\hline \multicolumn{6}{|l|}{ Annen problematferd, $t 1$} \\
\hline Nasking/stjeling & 256 & $(23,6)$ & 45 & $(31,0)$ & 0,050 \\
\hline Gjentatt sniking & 267 & $(24,6)$ & 41 & $(28,3)$ & 0,342 \\
\hline Gjentatt lyving & 206 & $(19,3)$ & 47 & $(32,4)$ & $<0,001$ \\
\hline Hyppig skulking & 243 & $(22,4)$ & 145 & $(29,0)$ & 0,079 \\
\hline
\end{tabular}

\section{Partnervold og opplevd kvalitet} av parforholdet

En nyere metaanalyse avdekket at sammenhengen mellom utøvelse av partnervold og opplevelsen av at parforholdet fungerte dårlig samlet sett var relativt svak - særlig for kvinner (12). Også den aktuelle studien avdekket negative korrelasjoner mellom kvinnenes voldsbruk og opplevd kvalitet av parforholdet. Samtidig var resultatene for de kvinnene som hadde angrepet partneren sin interessante i seg selv. $58(53 \%)$ av dem ga uttrykk for at partneren var en god støttespiller og at vedkommende også godtok dem fullt ut - både deres gode og deres dårlige sider. Videre svarte 65 av disse kvinnene (59\%) at parforholdet deres alt $i$ alt enten var «svært bra» eller at de «ikke kunne hatt det bedre» (tab 2). Andre funn pekte $\mathrm{i}$ retning av at kvinner $\mathrm{i}$ forhold med gjensidig voldsbruk var noe mindre tilfredse enn dem som var alene om å utøve vold, men forskjellene var ikke signifikante.

Selv om kvinnenes subjektive vurderinger ikke sier noe om hvordan parforholdet oppleves for den andre parten, kan ovennevnte funn likevel tyde på at fysiske angrep forekommer i relasjoner som ellers fungerer rimelig bra. Dette må ses i sammenheng med at den partnervolden som ble kartlagt, neppe var særlig grov. De hyppigst rapporterte tilfellene dreide seg om en og annen ørefik, mens ytterst få kvinner hadde bitt, sparket eller slått partneren sin mange ganger eller blitt utsatt for dette selv.

Denne studien bidrar til å understreke at partnervold er et heterogent fenomen og at undersøkelser av normalbefolkningen i liten grad fanger opp mishandling i ordets rette forstand (13, 14). Archers (1) omfattende metaanalyse avdekket dessuten at det særlig er blant godt voksne mennesker man finner den groveste partnervolden - ikke blant unge i etableringsfasen, som denne undersøkelsen dreide seg om.

\section{Aggressivitet og utagerende atferd}

Selv om partnervolden $i$ all hovedsak var lavfrekvent og trolig mindre alvorlig, skilte utøverne seg markant ut med hensyn til ulike mål på aggressivitet. I langt større grad enn kvinner ellers hadde disse kvinnene sterke følelser av undertrykt sinne, et hissig temperament og et høyt nivå av selvvurdert aggressivitet. I samsvar med tidligere longitudinell forskning (15-17) var dessuten aggressiv atferd $\mathrm{i}$ tenårene $(\mathrm{t} 1)$ prospektivt relatert til bruk av vold mot en partner $i$ ung voksen alder (t2). Både slåssing, hærverk, mobbing og verbal aggressivitet på t1 ga signifikante utslag, og sammenhengene var gjennomgående relativt sterke. Tilsvarende analyser av ikke-aggressiv problematferd avdekket et mindre konsistent mønster, men resultatene pekte likevel i samme retning.

Tidligere forskning har vist at både menn og kvinner som utøver partnervold, er generelt mer aggressive og utagerende enn dem som ikke gjør det (15-18). En rekke andre felles kjennetegn og risikofaktorer er også avdekket. Det er derfor blitt hevdet at mye av partnervolden trolig har felles etiologi på tvers av kjønn, og at mange av årsaksfaktorene antakelig er de samme som for annen vold og utagering. Tiltak som forebygger atferdsproblemer og destruktive former for aggresjon kan følgelig tenkes å redusere risikoen for å utøve partnervold - for menn så vel som for kvinner.

\section{Selvforsvar}

Funn fra store befolkningsundersøkelser og fra tallrike studier av andre ikke-kliniske utvalg indikerer at prevalensen for utøvelse av «mild» og moderat grov partnervold er omtrent lik for kvinner og menn (1, 3-5). Flere har i den forbindelse tatt i til orde for at slike funn er tilslørende fordi voldens kontekst og mening i stor grad er kjønnsspesifikk (19-21). Selvforsvar er i den sammenheng blitt løftet frem som en viktig forklaring på hvorfor også kvinner, og ikke bare menn, utøver vold i parforhold.

I denne studien var ensidige angrep fra kvinnenes side det mest utbredte voldsmønsteret. Mye av volden handlet derfor neppe om å beskytte seg mot partnerens fysiske angrep. I relasjoner der angrepene gikk begge veier, er det derimot mulig at kvinnenes voldsbruk i stor grad var selvforsvarsmotivert. På den annen side var kvinnenes voldsbruk - også den som fant sted i forhold der volden var gjensidig - nær knyttet til aggressivitet og utagerende atferd mer generelt. Det er derfor nærliggende å anta at det som regel er andre motiver enn selvforsvar som får unge kvinner til å angripe partneren sin.

Internasjonal forskning gir heller ingen klar støtte til antakelsen om at kvinners voldsbruk i hovedsak handler om å forsvare seg mot fysisk utagering fra partnerens side (21-23). Et bredt spekter av følelser og motiver synes å ligge til grunn for kvinnenes voldsutøvelse, herunder sinne, frustrasjon og sjalusi samt behovet for kontroll og for å få oppmerksomhet. Trakassering og annen psykisk vold fra partnerens side synes også å være viktige utløsende faktorer. I en viss forstand kan derfor selvforsvar likevel være et sentralt motiv - ikke for å avverge fysisk fare, men for å beskytte seg mot krenkelser som truer selvfølelsen.

\section{Begrensninger}

Denne studien må tolkes med forbehold, ikke minst fordi kvinnene i utvalget var svært unge. Drøyt halvparten var verken gift eller samboende, og vold som utspiller seg i langvarige, forpliktende samliv, har etter alt å dømme en annen betydning enn den som foregår i mindre etablerte forhold. Det må også understrekes at undersøkelser av mishandlingsforhold fanger opp en voldsvirkelighet med andre kjennetegn og en annen kjønnsprofil $(13,14)$ enn den som ble beskrevet her.

Studien inkluderte kun to parvise spørsmål om partnervold. Hvis et bredere spekter av aggressiv atferd var blitt kartlagt, ville forekomsten av falskt negative tilfeller ha vært lavere og voldsprevalensene tilsvarende høyere. En annen svakhet har med teststyrke å gjøre. De to utøvergruppene inkluderte få individer, hvilket øker risikoen for type 2feil. At forskjellene mellom kvinner som rapporterte henholdsvis ensidig og gjensidig voldsbruk bare unntaksvis var signifikante, må ses i lys av denne begrensningen. 
Videre var datamaterialet forholdsvis gammelt. Selv om partnervoldens omfang og kjennetegn neppe har endret seg markant siden 1999, kan det likevel ikke utelukkes. På den annen side hadde undersøkelsen flere fortrinn, herunder en relativt høy responsrate, en longitudinell design og et rikt tilfang av relevante data.

Datamaterialet som denne studien bygger på, ble innhentet og tilrettelagt av forskningsinstituttet NOVA, hovedsakelig med midler fra Norges forskningsråd.

\section{Hilde Pape (f. 1960)}

er dr.psychol. og arbeider som forsker ved Nasjonalt kunnskapssenter for vold og traumatisk stress (NKVTS). Rus og vold er sentrale forskningstemaer. Hun har også en bistilling ved Statens institutt for rusmiddelforskning (SIRUS).

Ingen oppgitte interessekonflikter.

\section{Litteratur}

1. Archer J. Sex differences in aggression between heterosexual partners: a meta-analytic review. Psychol Bull 2000; 126: 651-80.

2. Swan SC, Gambone LJ, Caldwell JE et al. A review of research on women's use of violence with male intimate partners. Violence Vict 2008; 23: 301-14.
3. Carney M, Buttell F, Dutton D. Women who perpetrate intimate partner violence: a review of the literature with recommendations for treatment. Aggress Violent Behav 2007; 12: 108-15.

4. Fiebert MS. References examining assaults by women on their spouses or male partners: an annotated bibliography. Sex Cult 2009; 8: 273-86.

5. Bookwala J, Sobin J, Zdaniuk B. Gender and aggression in marital relationships. A life-span perspective. Sex Roles 2005; 52: 797-806.

6. Pape H. Vold og krenkelser i unge menneskers parforhold. Tidsskr Nor Lægeforen 2003; 123: 2016-20.

7. Strand NP, von Soest T. Young in Norway - longitudinal. Documentation of design, variables, and scales. Oslo: NOVA, 2007

8. Straus MA. Measuring intrafamily conflict and violence: the Conflict Tactics Scale. J Marriage Fam 1979; 41: 75-88

9. Speilberger CD. Professional manual for the State-Trait Anger Expression Inventory. Odessa Psychological Assessment Resources, 1996.

10. Bem SL. The measurement of psychological androgyny. J Consult Clin Psychol 1974: 42: $155-62$.

11. Whitaker DJ, Haileyesus T, Swahn M et al. Differences in frequency of violence and reported injury between relationships with reciprocal and nonreciprocal intimate partner violence. Am J Public Health 2007; 97: 941-7.

12. Stith AM, Green NM, Smith DB et al. Marital satis faction and marital discord as risk markers for intimate partner violence: a meta-analytic review. J Fam Violence 2008; 23: 149-60.

13. Johnson MP. Patriarchal terrorism and common couple violence. Two forms of violence against women. J Marriage Fam 1995: 57: 283-94.

14. Johnson MP. Ferraro KJ. Research on domestic violence in the 1990s: making distinctions. J Marriage Fam 2000; 62: 948-63

15. Giordano PC, Millhollin TJ, Cernkovic SA et al.
Delinquency, identity and women's involvement in relationship violence. Criminology 1999; 37 $17-40$.

16. Moffitt TE, Kreuger RF, Caspi A et al. Partner abuse and general crime: how are they the same? How are they different? Criminology 2000; 38: 199-232.

17. Magdol L, Moffitt TE, Caspi A et al. Developmental antecedents of partner abuse: a prospective-longitudinal study. J Abnorm Psychol 1998; 107. 375-89.

18. Felson RB, Lane KJ. Does violence involving women and intimate partners have a special etiology? Criminology 2010; 48: $321-38$.

19. Conradi L. Geffner R. Introduction to part II of the special issue on Female offenders of intimate partner violence. J Aggress Maltreat Trauma 2009; 18: $667-71$

20. Swan SC, Snow DL. The development of a theory of women's use of violence in intimate relationships. Violence Against Women 2006; 12: 1026-45.

21. Dasgupta SD. A framework for understanding women's use of nonlethal violence in intimate heterosexual relationships. Violence Against Women 2002; 8: 1364-89

22. Bair-Merritt MH, Crowne SS, Thompson DA et al. Why do women use intimate partner violence? A systematic review of women's motivations. Trauma Violence Abuse 2010; 11: 178-89.

23. Flynn A, Graham K. «Why did it happen?» A review and conceptual framework for research on perpetrators' and victims' explanations for intimate partner violence. Aggress Violent Behav 2010: 15 239-51.

Mottatt 31.1. 2011, første revisjon innsendt 16.6. 2011, godkjent 4.8. 2011. Medisinsk redaktør Are Brean. 